\title{
The Effects of Behavioral Biases on Investment Performances of Individual Investors in the Indonesian Stock Market
}

\author{
Insuk Cho, Dony Abdul Chalid \\ \{vrai4u@naver.com, abdulchalid@yahoo.com\} \\ Master of Management, Universitas Indonesia, Faculty of Economics and Business, Universitas \\ Indonesia,
}

\begin{abstract}
This paper identifies the existences of behavioral biases in the Indonesian stock market and examines the effect of the behavioral biases on individual investment performance. We use quantitative analysis approach to explore our research purpose. To be specific, individual investors in Indonesia have behavioral biases of overconfidence bias, loss-aversion bias, anchoring and adjustment bias, mental accounting bias and confirmation bias. In addition, we find that confirmation bias and mental accounting bias are positive relationship with investment performance, whereas loss-aversion bias and anchoring and adjustment bias are negative significant relationship with investment performance.
\end{abstract}

Keywords: Behavioral finance, Behavioral bias, Indonesian stock market, Investment performance

\section{Introduction}

The Indonesian market, with its population of over 269 million people and diverse resources, is a very exciting and promising capital market among emerging markets. In recent years, various investors have participated in the Indonesian stock markets. According to Indonesia Stock Exchange's report, the total number of individual stock investors were 851,903 as of December 28, 2018, which is a 35 percent increase over last year (Source: IDX, 2018). As individual investors are increasing, they can have considerable power to affect the Indonesian stock market.

Most of the investment returns of individual investors are not as high as those of institutional investors. This is because individual investors have less information than institutional investors. Moreover, even if they have information or methodology of analysis of stock, the consequences are limited because human psychology affects investors' decisionsmaking process. Human can be easily exposed to biases. These biases can have a negative impact on economically rational decision [1]. The studies on behavioral bias of individual are being conducted very actively recently, but in Indonesia, not yet been conducted sufficiently. Therefore, the study of behavioral biases of individual investors and efforts to reduce these biases will be very important to the understanding of the Indonesian stock markets 


\section{Theortical background}

Behavioral finance economists argued that some financial phenomena, such as market abnormalities and short-term fluctuations, cannot be fully explained using classic financial models such as efficient market hypothesis and CAPM. Most of classical models assumed economic investors are rational that means economic investors are unbiased in processing of available information. Also, their decision-makings meet utility maximization. In addition, markets are so efficient that the securities prices can reflect all information available without delay[2]. These are stories of ideal world and too normative ways. So, as a critique of traditional theory, behavioral economists use alternative ways that is, descriptive approach. The main concern of behavioral economists is to intuitively explain phenomena related to humans with bounded rationality. [3] make public the prospect theory, which considers how individual perceive the prospects in their framing, how individual evaluate gain and loss, how individual compare uncertain results.

Several researches have studied the existences of behavioral biases at various markets regions and the effect of behavioral biases on decision-making process. [4] introduce existence of anchoring \& adjustment biases at probabilistic situations. There is significant relationship between gender and overconfidence bias in US common stock market [5] and they also find out investors in US market tend to do availability bias in decision-making[6]. Recently, [7] find out investment experience, age and occupation are the significant components that affect behavioral biases in a study of the effects of demographic background and financial literacy on behavioral bias.

\section{Research methodology}

\subsection{Research model and Material}

The research has two main purposes. First of all, we will check whether behavioral biases are actually occurring among respondents in Indonesia stock markets and find what is the dominant behavioral bias through frequency-testing. Secondly, we will identify the relationships with behavioral biases and investment performances through Multiple Regression Analysis.

Hypothesis: Behavioral biases have significant effect on the investment performance of individual investors

We use a convenience sampling method. Survey was conducted for adult men and women who have investment experience living in Indonesia 15, February 9, March in 2019, through both online and offline survey. Total number of samples to analyze is 181 .

\subsection{Variable operationalization}

The principal independent variables of this study are behavioral biases. Regarding independent variable, we constructed the 5 points Likert scales by combining the ordinal scales and regarded this Likert scale as the interval scale. With these scales, regression 
analysis can be used. The dependent variable is the investment performance, which is constructed by combining the ordinal scales ( 5 points Likert scales).

\section{Results and Discussion}

\subsection{Demographic Profile of the Respondents}

The demographic characteristics of the subjects are as shown in the Figure 1. In the case of gender, $108(59.7 \%)$ are male and $73(40.3 \%)$ are female. The age groups 19 to 28 years $(43.1 \%)$ and 29 to 38 years $(28.7 \%)$ take the highest portion of the sample. About the occupations, various occupational groups are represented[8]. The largest occupation group is Financial/ Accounting group (26.5\%). Regarding annual incomes, 39.8\% of respondents earned US\$ 5,000 19,999. The second largest group earned US\$20,000 49,999 $(21.5 \%)$. As for the final education level of the survey participants, the bachelor degree is the most (56.9\%), follow by master degree (23.2\%), high school graduate (10.5\%), no diploma (5.5\%), and doctor degree (3.9\%), respectively. Regarding stock investments experience, the less than two years is the largest portion of respondents (39.8\%) and the investment experience of 2-5 years is behind $(32 \%)$.
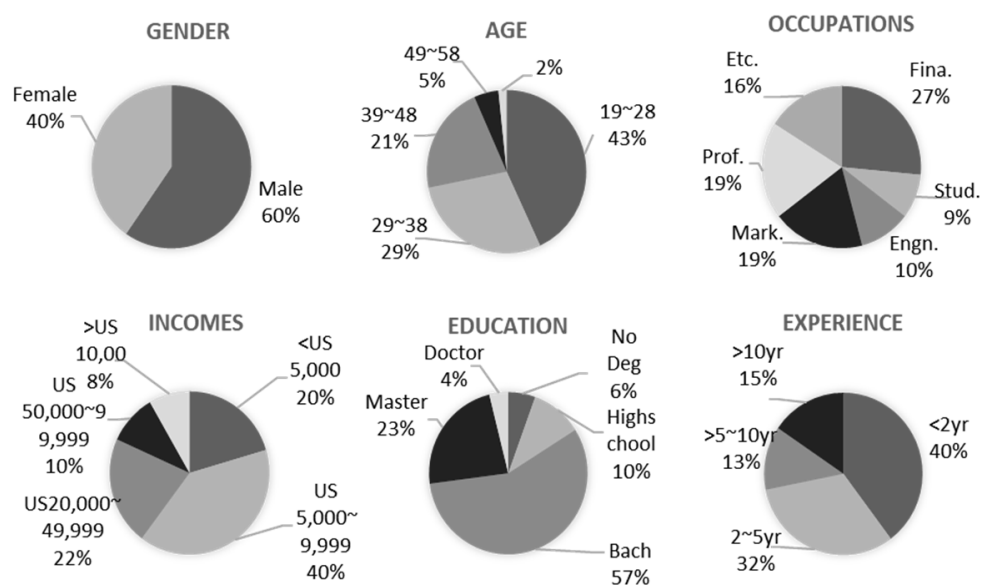

Figure. 1. Demographic Profile of the Respondents 


\subsection{Descriptive Statistics of Principal Variables \& Assessments for Methodology}

Table 1 shows the descriptive statistics of main variables. Among the Indonesian investors, the most dominant behavioral bias is overconfidence bias (3.91 point out of 5 point), followed by loss-aversion bias. Given that the neutral point is 3, the investors also have an anchoring \& adjustment bias, mental accounting bias and confirmation bias. The results of appearance of behavioral biases are consistent with previous researches[9]. A matter of note is that self-control bias is below 3 point $($ mean $=2.49)$ suggesting respondents less tend to have self-control bias. We can find an interpretation of this result in previous study. [10] Explain that many individuals who have limited budgets tend to reduce their current spending. Given the GDP per capita of Indonesia is $\$ 4,130$ (Source: WORLD BANK, 2018), it can be concluded that there is still not enough accumulation of wealth for consumption. As a result, current low propensity to consume plays a role in preventing self-control bias. The results of questionnaires about the investors' investment performance from their point of view is an average of 3.22 points (standard deviation $=0.77$ ) out of 5 points. Considering the 3 point is neutral, investors generally think neutral in their investment performance.

The Kaiser-Meyer-Oklin (KMO) Measure of Sampling Adequacy is 0.720, and the Bartlett's Test of Sphericity shows that the $p$-value is less than 0.05 , suggesting that the factor analysis model is appropriate. Also, the cumulative variance is $60.81 \%$, indicating that the 7 explanatory factors have high explanatory power. Generally, it is judged that reliability is exit if the coefficient Cronbach's alpha is more than 0.6.

Table 1. Descriptive Statistics of Principal Variables \& Assessments for Methodology

\begin{tabular}{ccccccc}
\hline Variable* & $\mathrm{N}$ & Min & Max & Mean & S.D. & Cronbach's $\sigma$ \\
\hline MA & 181 & 1.00 & 5.00 & 3.52 & 0.90 & 0.723 \\
CON & 181 & 1.00 & 5.00 & 3.50 & 0.89 & 0.683 \\
ANC & 181 & 1.50 & 5.00 & 3.77 & 0.78 & 0.707 \\
LA & 181 & 1.00 & 5.00 & 3.78 & 0.87 & 0.702 \\
OC & 181 & 2.50 & 5.00 & 3.91 & 0.56 & 0.627 \\
SC & 181 & 1.00 & 5.00 & 2.49 & 0.91 & 0.706 \\
IP & 181 & 1.00 & 5.00 & 3.22 & 0.77 & 0.781 \\
\multicolumn{6}{c}{ Cumulative \%=60.807, $\% M O=0.720$, Bartlett's $x^{2}=860.570(p<0.001)$} \\
\hline
\end{tabular}

$* \mathrm{MA}=$ mental accounting bias, $\mathrm{CON}=$ confirmation bias, $\mathrm{ANC}=$ anchoring and adjustment bias, $\mathrm{LA}=$ loss-aversion bias, $\mathrm{OC}=$ overconfidence bias, $\mathrm{SC}=$ self-control bias, and $\mathrm{IP}=$ investment performance.

\subsection{Multiple regression analysis}

Table 2 indicates the results of multiple regression analysis for investigating the effect of behavioral biases on investment performance and Durbin-Watson test for independence of residuals. The results are as follows. First, mental accounting bias and confirmation bias show a significant positive relationship with investment performance. Second, anchoring and adjustment bias and loss-aversion bias have negative relationship with investment performance, respectively. In other word, respondents who have more mental accounting bias 
and confirmation bias tend to show better investment performance, and people with more anchoring and adjustment bias and loss-aversion bias tend to show poor investment performance.

Comparing the absolute values of the standardized coefficients $(\beta)$, it appears that each behavioral bias effect on investment performance in order of mental accounting bias, lossaversion bias, anchoring and adjustment bias, and confirmation bias.

These results are generally consistent with previous studies[11] that behavioral biases affect the investment performance. The noticeable points are that investors who have confirmation bias and mental accounting bias are more likely to be satisfied with their investment performance. This is inconsistent with previous studies[12] that both mental accounting bias and confirm bias prevent investors from diversifying their investment portfolio and having poor investment results. There are several reasons for this result. First, the investment performance in our study is measured from the investors' point of view, so it may be different from the objective return on investment. This research more focuses on investor's subjective satisfaction. Second, regarding mental accounting bias and investment performance, mental accounting bias can positive impact on investment performance. This is because investor who has a mental account can manage their investment more firmly according to their goal and risk tolerance.[13] introduces the goals-based investment strategy that most appropriate investment way considering investment purpose and risk tolerance of each individual. Finally, regarding the confirmation bias, recently, Indonesian stock markets are positive situation, therefore, some behavioral biases that stretch the meaning of current good situation such as confirmation bias make positive relationship with investment performances.

Table 2. Multiple Regression Analysis on Investment Performance across Behavioral Biases.

\begin{tabular}{|c|c|c|c|c|c|c|c|}
\hline DV & IV & $B$ & S.E. & $\beta$ & $t$ & $p$ & $V I F$ \\
\hline \multirow{7}{*}{ IP } & Cons & 3.176 & 0.442 & & 7.178 & 0.000 & \\
\hline & MA & 0.372 & 0.065 & 0.435 & 5.755 & 0.000 & 1.499 \\
\hline & CON & 0.168 & 0.064 & 0.195 & 2.616 & 0.010 & 1.458 \\
\hline & ANC & -0.196 & 0.071 & -0.198 & -2.761 & 0.006 & 1.347 \\
\hline & LA & -0.316 & 0.058 & -0.358 & -5.400 & 0.000 & 1.151 \\
\hline & $\mathrm{OC}$ & 0.046 & 0.087 & 0.033 & 0.523 & 0.602 & 1.055 \\
\hline & SC & -0.040 & 0.056 & -0.048 & -0.715 & 0.476 & 1.161 \\
\hline \multicolumn{8}{|c|}{$F=14.706\left(p=0.000^{b}\right), R^{2}=0.336,{ }_{a d d} R^{2}=0.314$, Durbin-Watson $=1.484$} \\
\hline
\end{tabular}

\section{Conclusion}

This research reveals the existence of behavioral biases in Indonesian stock market. The results are consistent with previous studies that investors are not always rational. Instead, they are influenced by cognitive ability such as mathematical probability and unconscious emotions such as loss-aversion and overconfidence in the investment process of decision-making[14]. These behavioral biases can make sub-optimal investment decision-making. In addition, we find the significant relationships between some kinds of behavioral biases and the investment performance. 
This study will help policy makers who create the sound investment environment for market participants of Indonesia. In the perspective of individual investors of Indonesian stock market, individual investors who can identify their own behavioral biases and know how their behavioral bias influences investment decisions will be able to make more rational decisions. For financial advisors, this research can make a good advisory relationship with the client through the suggestion of a financial goal that takes into account the psychological factors of the clients[15].

Our research has limitations in finding objective investment performance. The reason is that in order to obtain objective investment result data, various variables affecting investment results, such as investment time period, amount of investment and unique circumstances, must be controlled. Future studies should overcome these limitations and explore more behavioral biases among Indonesia stock market participants not covered in our study. 


\section{References}

[1] A. Tversky and D. Kahneman, "Judgment under uncertainty: Heuristics and biases," Science (80. )., 1974, doi: 10.1126/science.185.4157.1124.

[2] B. G. Malkiel and E. F. Fama, "EFFICIENT CAPITAL MARKETS: A REVIEW OF THEORY AND EMPIRICAL WORK*," J. Finance, vol. 25, no. 2, pp. 383-417, May 1970, doi:

10.1111/j.1540-6261.1970.tb00518.x.

[3] D. Kahneman and A. Tversky, "Kahneman \& Tversky (1979) - Prospect Theory - An Analysis

Of Decision Under Risk.pdf," Econometrica. 1979, doi: 10.2307/1914185.

[4] E. J. Joyce and G. C. Biddle, "Anchoring and Adjustment in Probabilistic Inference in Auditing," J. Account. Res., 1981, doi: 10.2307/2490965.

[5] B. M. Barber and T. Odean, "Boys will be boys: Gender, overconfidence, and common stock investment," Q. J. Econ., 2001, doi: 10.1162/003355301556400.

[6] B. M. Barber and T. Odean, "All that glitters: The effect of attention and news on the buying behavior of individual and institutional investors," Rev. Financ. Stud., 2008, doi:

10.1093/rfs/hhm079.

[7] H. K. Baker, S. Kumar, N. Goyal, and V. Gaur, "How financial literacy and demographic variables relate to behavioral biases,” Manag. Financ., vol. 45, no. 1, pp. 124-146, 2019, doi: 10.1108/MF-01-2018-0003.

[8] C. Gadarowski, "Financial Press Coverage and Expected Stock Returns," SSRN Electron. J., no. September 2000, 2005, doi: 10.2139/ssrn.267311.

[9] Alrabadi, D. W. H., Al-Abdallah, S. Y., \& Aljarayesh, N. I. A.: Behavioral Biases and Investment Performance: Does Gender Matter? Evidence from Amman Stock Exchange. Jordan Journal of Economic Sciences 5(1): 77-92 (2018).

[10] J. Ameriks, A. Caplin, and J. Leahy, "Wealth accumulation and the propensity to plan," Quarterly Journal of Economics. 2003, doi: 10.1162/00335530360698487.

[11] G. Chen, K. A. Kim, J. R. Nofsinger, and O. M. Rui, "Trading performance, disposition effect, overconfidence, representativeness bias, and experience of emerging market investors," J. Behav. Decis. Mak., 2007, doi: 10.1002/bdm.561.

[12] R. J. Fuller, "Behavioral Finance and the Sources of Alpha,” J. Pension Plan Invest., 1998.

[13] J. L. . Brunel, "Revisiting the Asset Allocation Challenge Through a Behavioral Finance Lens," J. Wealth Manag., 2003, doi: 10.3905/jwm.2003.320479.

[14] H. M. Shefrin and M. Statman, "Explaining investor preference for cash dividends," J. financ. econ., 1984, doi: 10.1016/0304-405X(84)90025-4.

[15] Y. Kroll, H. Levy, and A. Rapoport, "Experimental Tests of the Separation Theorem and the Capital Asset Pricing Model.," Am. Econ. Rev., 1988. 